\title{
REPRODUCTIVE FUNCTION IN HYBRID POULTRY. III. AN IMPACT OF BREEDER FLOCK AGE
}

\author{
(review)
}

\section{Yu.I. ZABUDSKII}

Russian State Agrarian Correspondence University, 1, ul. Fuchika, Balashikha, Moscow Province, 143900 Russia, email zabudsky@hotmail.com

Received February 1, 2016

\begin{abstract}
For the first time recent findings on reproductive function in poultry as influenced by breeder age are summarizes and discusses in Russian. The focus is on changes in incubation eggs, metabolism, growth and development of the chicken at pre- and postnatal ontogenesis. In 511 breeder flocks from the Netherlands in 2004-2006 (7.5 million eggs, over 24,000 batches) the breeder age has been proved to be dominant for hatchability compared with the environment conditions and poultry genotype (H. Yassin et al., 2008). When aging, the breeders lay eggs bigger in size with an increased yolk to albumen percentage. So, this ratio grew from 0.5 to 0.6 in 26 to 31 week old ducks (T.J. Applegate et al., 1998), from 0.4 to 0.5 in 30 to 60 week old Hybrid and Nicholas turkey lines (J.A. Hamidu et al., 2011), and from 0.4 to 0.5 in 26 to 35 week old breeder hens (Arbor Acres) (E.D. Peebles et al., 2000). Shell quality becomes significantly worse, including loss in thickness and strength (P.P. Tsarenko et al., 2012). The egg weight loss in the course of incubation is inversely proportional to the shell thickness. These alterations are a consequence of disorders of calcium metabolism in the body of aging layers. For example, blood calcium levels in Lohmann White chickens reduced from $4.82 \mathrm{mmol} / \mathrm{l}$ in 18 week old hens to $2.73 \mathrm{mmol} / \mathrm{l}$ at the end of laying period (80 weeks) (T.I. Sereda et al., 2011). For young breeders the lipoprotein assimilation in embryos is lower (M.A. Latour et al., 1998). For older breeders the metabolic heat produced by embryo increases, and an increased egg shell permeability can lead to bacterial contamination (A. Rodríguez-Navarro et al., 2013). There is a parabolic change in main indicators of hen reproductive function when aging. For meat hens of 26-30-, 34-38- and 58-62 weeks of age the fertility and hatchability were 92.7, 96.7, 80.3\% and 84.1, 87.9, 83.4\%, respectively (J.A. Hamidu et al., 2007; H. Bergoug et al., 2013), and an average fecundity was $17.6,18.1$ and 5.5 chicks (A.K. Osmanyan, 2014). The incubation time for the eggs laid in the second half of laying period is shorter compared to that in the first half (A.M. Ulmer-Franco et al., 2010). In the chickens hatched from the eggs laid at the end of laying period a probability of microbial infection increases due to underdeveloped navel (H. Yassin et al., 2009). For older breeders the chickens' weight was higher while the viability decreased. So, for 28 - and 65 -week hens the embryo mortality reached 2.7 and $8.9 \%$, and the weight at hatchling was 36.5 and $45.3 \mathrm{~g}$, respectively (B. Yilmaz-Dikmen et al., 2009). For meat breeders of 25-, 38-44- and 60 weeks of age the mortality among chickens for the first week after hatching reached 1.82, 1.02 and $1.20 \%$, respectively (H. Yassin et al., 2009). Due to the differences in embryo growth and development for young and old breeders, the eggs should be pre-sorted prior to incubation with regard to egg weight and breeders' age to provide uniform adaptiveness in the progeny. Proper temperature and humidity during incubation can be helpful to correct water evaporation and metabolic heat in the eggs originated from breeders of different age.
\end{abstract}

Keywords: poultry, breeder flock age, eggs, incubation, embryo metabolism, incubation mode, quality of chicks

Blood concentrations of luteinizing and follicle-stimulating hormones are decreased in laying hens with advancing age. This relation may result from a decrease in sensitivity of the hypothalamus to light stimulation [1] or reduced release of gonadotropin-releasing hormone due to aging [2]. Similar changes are observed in the concentrations of progesterone and estradiol in the beginning, middle, and at the end of the egg production period, i.e., respectively, 4.3, 3.8, $1.6 \mathrm{ng} / \mathrm{ml}$ and $184.9,181.7,66.7 \mathrm{pg} / \mathrm{ml}$ [3]. The number of yellow follicles is 
higher in young pullets than in old hens [4]. A slower growth of follicles with age may result from decreased concentrations of follicle stimulating hormone. Furthermore, the sensitivity of large follicles to LH reduces [5].

The major characteristics of hatching eggs (weight, composition and the ratio of ingredients, shell thickness and porosity, the incubation outcomes, the quality of the obtained young stock) are subject to changes as the population in the breeder flock ages [6-11]. The analysis of the incubation outcomes in $37 \%$ of eggs from meat chickens in the Netherlands in 2004-2006 (7.5 million eggs from 511 breeder flocks) showed that the following factors had the dominant influence on the hatchability (listed in decreasing order of importance): the breeder age, duration of egg storage, and poultry genotype [12].

For the first time in the Russian-language specialized literature, this review summarizes and discusses the investigations on the characteristics of reproductive function in highly productive poultry depending on the breeder flock age. The focus has been made on changes in the quality of hatching eggs and the resulting young stock, as well as on the metabolism of embryos according to the mothers' age.

The phenomenon of increased weight of eggs from aging laying fowls was found virtually in all types of poultry. For example, in Cobb 500 meat chickens at the age of 29 and 59 weeks, egg weight was 53.8 and 71.3 g, i.e. increased by $32.5 \%$ [13]. This value increased by $13.2 \%$ in Hy-Line Brown layers aged from week 25 to 65 [14], by $10.0 \%$ in Peking ducks aged from week 26 to 42 [15], and by $8.1 \%$ in turkeys from British United Turkeys of America at weeks 33 to 43 [16].

With the increase of the absolute weight of eggs, the same process affects the egg white, yolk and shell, but these changes are asynchronous. Weight gain in egg yolk is more pronounced than in the egg white, which is expressed by the yolk-white ratio [7]. Thus, this value increased from 0.5 to 0.6 in ducks from week 26 to week 31 [15], from 0.4 to 0.5 in 30 - to 60-week turkeys of Hybrid and Nicholas lines [17], and from 0.4 to 0.5 in Arbor Acres chickens aged week 26 to week 35, whereas the plateau [18] was recorded at the age of 35 to 47 weeks [18]. In Single Comb White Leghorn hens aged 28 to 78 weeks, this value as percentage ranged from 36.6 to 46.6 ; it decreased to 40.8 (19) upon reaching 97 weeks of age. An increase in egg weight observed with hens aging is a consequence of gradual failure in egg production intensity caused by decrease in the number of follicles that reach the final phase of rapid growth [20]. Therefore, each follicle has a larger proportion of the resulting yolk.

The eggshell quality changes with the age of the laying hens [10, 21]. The egg and eggshell weights in 61-week-old chickens of Xy-Line W36 cross (respectively, 58.9 and $4.9 \mathrm{~g}$ ) were increased compared to those at the age of 25 weeks (50.3 and $4.7 \mathrm{~g}$ ), however, the relative shell weight, its thickness and the impact strength decreased, respectively, from 10.6 to $9.6 \%$, from 0.33 to 0.31 $\mathrm{mm}$ and from 4.3 to $3.4 \mathrm{~kg} / \mathrm{cm}^{2}$ [22]. The eggshell thickness in 30 - and $60-$ week-old chickens of Cobb 500 cross was reduced from 0.37 to $0.36 \mathrm{~mm}$ (23). The impact strength in eggs from 76-week-old Lohmann White chickens decreased from 3.64 to 2.60 points compared to that in eggs from 28 - to 32-weekold hens [24].

Changes in the eggshell properties arise from disorders in calcium turnover in the body of the layers, which normally develop with age. Thus, serum calcium concentrations in the Lohmann White chickens decreased from $4.82 \mathrm{mmol} / \mathrm{l}$ in the prelaying period (18 weeks) to $2.73 \mathrm{mmol} / \mathrm{l}$ at the end of laying ( 80 weeks age), while in the mixture of the egg white and yolk the calcium content increased from 12.30 to $15.87 \mathrm{mmol} / \mathrm{kg}$ [25). The data showed that in the final pe- 
riod of egg production absorption of calcium from food reduces, and the reserves of bone tissues deplete. This triggers accelerated rates of calcium transport in the blood-egg system. Duodenal calcium uptake rate in the laying hens at 37 to 58 weeks of age decreased from 408 to $329 \mathrm{pmol} / \mathrm{mg}$ tissue per min, the ash content in the femur fell from 50.8 to $47.6 \%$, and shell thickness was reduced at week 22 to week 57 from 403 to $373 \mathrm{~mm}$ [26]. In grey Japanese quail at 10 and 32 weeks of age, calcium levels in the shell were 37.6 and $31.2 \%$ [9].

Humidity in the incubator cabinets should be appropriately adjusted taking into account changes in the eggshell quality. Significant weight losses in hatching chicken eggs were observed due to increasing flow of water vapor through the shell, i.e. from 4.21 to $5.44 \mathrm{mg} /($ day $\cdot 100 \mathrm{~g} \cdot \mathrm{kPa})$ starting from the beginning of the egg use from young breeders to 77-week-old chicks [27]. The authors proved the need to increase the relative humidity in the incubator cabinets from 53 to $66 \%$ with hens aging during the first cycle of egg production.

The shell weight of eggs from 78-week-old Hisex Brown and Bovans Brown hens compared to 33-week-old pullets decreased, respectively, from 5.7 to $5.5 \mathrm{~g}$ and 5.3 to $5.2 \mathrm{~g}$, the nitrogen content fell from 0.33 to $0.28 \%$ in the shell, and from 0.35 to $0.31 \%$ in the inner shell membrane [28]. Furthermore, the eggshell became thinner. If in the early laying period (33-45 weeks) its thickness at the equator in eggs from Hisex Brown chickens was equal to on average 360.8 microns, in the final period (66-78 weeks) it was 346.9 microns. Decreased strength of the eggshell was registered, as well violations of its crystallographic texture with the aging of the layers that may be due to changes in the organic matrix [29].

The microflora penetrates the egg mainly through the pores in the eggshell. For example, Salmonella contamination of the surface of eggs from 32- and 58-week-old chickens was, respectively, 1.5-2.1 and 2.98 $\log \mathrm{CFU} / \mathrm{ml}$, depending on the duration of their storage after inoculation [30]. This is due to changes in the properties of the cuticle, closing the pores. During the entire period of the egg production its thickness, glycosylation and lipid content usually decrease [31]. As a result, the permeability of the eggshell in eggs from older mothers increases, resulting in a threat of bacterial contamination of the egg contents.

An increase in the egg weight, seen with advancing age of chickens, and related changes in absolute and relative values of the egg white and yolk weights affect their chemical composition. A. Nangsuay et al. [32] investigated small and large eggs from 29-week-old (58.3 and $65.6 \mathrm{~g}$ ) and 53-week-old (58.4 and $66.1 \mathrm{~g}$ ) Arbor Acres chickens. Both categories of eggs from young pullets had yolks with almost equal weight (15.9 and $16.1 \mathrm{~g}$ ), whereas larger eggs from older layers contained $1.9 \mathrm{~g}$, or $10 \%$, more yolk than the smaller ones. Larger and smaller eggs from older birds contained, respectively, $3.0 \mathrm{~g}$ (10.2\%) and $4.33 \mathrm{~g}(11.4 \%)$ less of the egg white than those from younger pullets. Opposite relations between the dry matter amounts and bird's age and egg weight were revealed.

The major stock of nutrients in an egg contains in its yolk, such as $70.6 \%$ of dry matter, $47 \%$ of protein, $99 \%$ of lipids, and the latter provide more than $90 \%$ of the energy used for embryogenesis [33]. The rates of lipid metabolism in the offspring both in the embryonic and post-embryonic periods change as their parents age. Low serum total cholesterol and high density lipoprotein cholesterol are typical for chicks from young pullets (compared to the peers who are the offspring from older hens) [34]. For example, high density lipoprotein cholesterol levels in chicks from 36-, 51- and 64-week-old hens were, respectively, $87.2,126.6$ and $102.7 \mathrm{mg} / \mathrm{dl}$. The data confirm findings of the studies [35], which demonstrated reduced yolk lipid absorption in embryos descendants from 36-week-old chickens as compared to 51- and 64-week chickens. 
The differences in the rates of lipid metabolism in the embryos, depending on the age of their mothers, are due to the kinetics of chemical reactions in the yolk sac. Thus, the $\Delta 6$ - and $\Delta 9$-long-chain fatty acids (FA) desaturation activities in the membranes of the yolk sac are increased in the early stages of yolk lipid assimilation in embryos from 36-week-old chickens [36]. As a result, linolenic acid is converted to arachidonic acid and stearic acid to oleic acid. The depression of the activities of $\Delta 5$ - and $\Delta 6$ fatty acid desaturases has been observed involving adrenocorticotropic hormone [37], which serves as a promoter of corticosterone production and participates in lipoprotein metabolism [38].

It appears that the small intestine in the embryos born to mothers of different age is unequally developed, and that underlies the identified metabolism variations. Villi of the duodenum and the jejunum in the day-old chicks produced from eggs laid by 48 -week-old Ross chickens were wider, and the jejunal ones even longer, than in the offspring from 29-week-old layers [39]. Consequently, the area of the surface absorbing nutrients was greater in the former than in the latter.

A lower relative weight of the yolk sac was registered in eggs from 26week-old hens compared to 28 - and 30-week layers, and it was, respectively, 17.8, 18.6 and $18.5 \%$ (incubation at $53 \%$ humidity) [40]. Lipid levels in the yolk of eggs from 26-week-old hens when incubated in the setter at $63 \% \mathrm{hu}$ midity were higher compared to those obtained after incubation at $53 \%$ humidity. However, during the incubation of eggs from 30 -week birds this value was lower at $43 \%$ humidity than at $53 \%$ or $63 \%$.

FAs added to the yolk during the vitellogenesis are the main source of energy and water for the developing embryos. The levels of stearic and arachidonic fatty acids in the yolk of fresh eggs from 26-week-old hens were higher than those in the yolk of eggs from 28- and 30-week-old chickens. The arachidonic FA amount was, respectively, 2.7, 1.8 and $1.8 \%$ [40].

Increased assimilation of FAs, such as palmitic acid, from the yolk sac was observed in the incubation setting with a humidity level at 53\%, compared to $43 \%$ or $63 \%$. This confirms the results of the studies [41] on the role of palmitic FA in the synthesis of embryo tissues. If chicken eggs are incubated at $37.5^{\circ} \mathrm{C}$, the optimal humidity is $53 \%$ [42).

E.E. OnbaŞılar et al. (43) differentiated eggs from 31- and 78-week-old ducks based on their weight: small (75-80 g), medium (81-85 g) and large ones (86-90 g). The albumen index was, respectively, 8.2, 7.9, 7.3 and 7.6, 7.0, $6.3 \%$. The levels of oleic and linoleic FAs in the yolk of eggs of all categories decreased with the age of the mothers and averaged to $45.9 \%$ and $43.3 \%$ (in 31 week-old ducks) and $20.4 \%$ and $18.3 \%$ (in 78-week-old ducks). On the contrary, the concentrations of myristic, palmitic and stearic FAs and the sum of saturated acids increased. In meat chickens, the amounts of myristic and linoleic fatty acids in egg yolks decreased with age (28, 44 and 65 weeks), respectively, from 0.34 to 0.24 and from 21.60 to $13.87 \mathrm{mg} / \mathrm{g}$ [44].

The same was observed in meat hens regarding the fertility rates (a decrease from 97.83 to $73.00 \%$ ) and hatching rate (from 92.00 to $62.78 \%$ ). Conversely, the embryonic mortality during the incubation period, as well as the live weight of the one-day chickens increased, respectively, from 2.73 to $8.93 \%$ and from 36.58 to $45.31 \mathrm{~g}$ [44].

Fertility and hatchability of the eggs correlate with other characteristics of their quality. According to V.I. Fisinin et al. [7], when the yolk weight increased (from 18.92 to $23.31 \mathrm{~g}$ ), the weight of eggs, laid by meat chickens of the same age, also increased (from 62.83 to $70.09 \mathrm{~g}$ ), while during 60 weeks the egg production significantly decreased (from 119.76 to 109.83 pcs.), as well as the 
fertilization rates (from 94.2 to $79.47 \%$ ), however, hatchability rates remained practically unchanged. When the egg weight increased by $1.62 \mathrm{~g}$, the yolk weight increased by $1.00 \mathrm{~g}$, the fertilization rate decreased by $3.3 \%$, and the egg production was lower by 1.85 pcs per hen. The egg weight correlated with the hatchability rates, which were the highest $(\sim 96 \%)$ in medium eggs $(50-60 \mathrm{~g})$, whereas at 60-65 g and $70 \mathrm{~g}$, the hatchability rates decreased, respectively, by 5.9 and $13.5 \%$ [45]. In 2004-2006, in the Netherlands, when obtaining 7.5 million eggs from meat chickens at 25,31-36 and 65 weeks of age, the hatchability rates were, respectively, 66, 86 and $50 \%$ [12]. Such a significant change in one of the main indicators of the bird reproductive capacity due to the breeder flock aging are caused by the characteristics of offspring embryogenesis.

The study of embryogenesis in eggs with almost the same weight (64.4-64.8 g) from the Ross 308 and Cobb 500 chickens demonstrated high respiratory quotient in the offspring of 45-week-old birds (0.84) compared to the 29-, 34-, 40-, 55- and 59 -week-old hens $-0.65 ; 0.73 ; 0.76 ; 0.67$ and 0.72 , respectively [46].

The $\mathrm{O}_{2}$ consumption, $\mathrm{CO}_{2}$ production, respiratory quotient, and metabolic heat production were independent of the genotype during the entire period of incubation. However, there were differences in the values for an individual day. For example, on day 18, the eggs from the Ross 308 and Cobb 500 chickens assimilated $\mathrm{O}_{2}$ at 873.5 and $802.7 \mathrm{ml} /$ day and released the heat at 194.9 and $180.8 \mathrm{~mW} /$ day [46].

In Ross 308 and Cobb 500 chicks, the total heat production during the incubation period appeared to be identical, i.e. 1,728 and 1,712 $\mathrm{mW}$, respectively. A correlation was revealed between the metabolism rates in embryos and the age of laying hens. On average, the eggs from the 29-, 45-, 55- and 59-week-old chickens of both genotypes released, respectively, 1,712, 1,677, 1,808 and 1,832 $\mathrm{mW}$ of heat against only $1,601 \mathrm{~mW}$ in the eggs from $34-36$-week-old birds. It should be noted the phenomenon of increased heat production in the embryos, which are the offspring of 55- and 59-week-old chickens [46]. The same pattern in metabolic heat production is seen in turkeys [17]. For example, on day 27, in the eggs from 30-, 34-, 55- and 60-week-old chickens the heat release was 231 , 265, 288 and $307 \mathrm{mWm}$ respetively.

A. Nangsuay et al. [47] divided the eggs laid by the 29- and 53-week-old chickens within the ranges of 57-61 and 66-70 $\mathrm{g}$ and formed the batches of small and large eggs, respectively, from young ( $\mathrm{MM}$ and $\mathrm{KM}$ ) and old (MC and $\mathrm{KC}$ ) layers. The yolk-white ratio was increased in $\mathrm{MC}$ and $\mathrm{KC}(0.57$ and 0.55$)$, compared to MM and KM (0.44 and 0.29). Moreover, the greatest differences were registered between $\mathrm{KC}$ and $\mathrm{KM}$ hens. Due to the increased weight, the egg yolks from MC and KC contained more energy than MM and KM (274.3 and $310.24 \mathrm{~kJ}$ against 238.28 and $233.18 \mathrm{~kJ}$, respectively). Body weight (without residual yolk) of chicks, hatched from eggs of all batches, was identical. However, the dry matter amounts and fat contents in the residual yolk in the chicks from mothers of the older age group (compared to younger group) were higher, while protein levels lower. Starting from day 16 of the incubation, the MC and $\mathrm{KC}$ birds released more heat energy than the MM and $\mathrm{KM}$ hens. For example, from day 16 to day 18, such an increase for the MC hens compared to MM pullets was $22 \mathrm{~mW}$ per egg.

Hatching out as one of the crucial periods of embryogenesis [48] is accompanied by the distress of the embryo's neuroendocrine system, which is reflected by the increased functional activity of the thyroid gland and the hypothalamus-pituitary-corticoadrenal system [49]. The time from the start of incubation to the eggshell pipping and the total duration of the incubation, as well as the intensity of hatching out depend on the breeder flock age. 
The eggshell pipping and the hatching in 29-week-old Cobb 500 chickens began, respectively, 494.4 and 503.8 hours after laying eggs in the incubator, i.e. with a delay compared to eggs from 59-week-old birds with their 490.2 and 500.4 hours [13]. B.P. Hudson et al. in their study [50] established the following correlation on the same chicken cross: after 492 hours of incubation, the hatching was 79.9, 86.7, 91.7 and $85.2 \%$ in the eggs from 29-, 41-, 53- and 65-weekold laying hens, respectively. The hatching in the eggs from 44- and 72-week-old Isa-Vedette meat chickens began after 461 hours of incubation, being 6 hours later in 34-week-old pullets [8]. The average value after 485 hours of incubation of eggs from the laying hens of all ages was $71 \%$, but it was $58 \%$ in the batch of eggs from 72-week-old hens, and $77 \%$ in the eggs from the younger age groups. These data show that $94 \%$ of the produced chickens can be removed after 491 hours of incubation, thus avoiding the effects of a number of negative factors in the incubator cabinets, including substantially increased carbon dioxide and dust amounts in the air [51].

One reason for the extended period of incubation of eggs from young pullets is the decreased lipid metabolism in the embryos as compared to the offspring of older mothers [34, 35].

It should be noted that the duration of embryogenesis is determined not only by parent aging, but also by other factors, such as breeding for an increased productivity, which is typical for different types of poultry [52, 53].

Aging of the breeder flock is accompanied with the increasing weight of eggs produced from laying hens as well as the live weight of the chicks hatched from them, but their quality is reduced. Thus, when the weights of eggs from the 32- and 57-week-old Dekalb chickens were 56.2 and $63.3 \mathrm{~g}$, the weights of the day-old chicks were 38.3 and $43.0 \mathrm{~g}$, respectively [54]. Turkey chicks of the Universal cross hatched from eggs produced from 50-week-old mothers had higher live weight in their 14 weeks of age when compared to those produced from 37 and 46-week-old mothers [55]. According to J.L. McNaughton et al. [56], broiler cockerels (genotype not specified), produced from the eggs (47-54 and 57-62 g) of 29-week-old pullets, weighed 33 and $37 \mathrm{~g}$ on their first day of life, and 1,985 and 2,044 $\mathrm{g}$ after 8 weeks of incubation, while cockerels hatched from 57-62 and 67-74 g eggs laid by 58-week hens, were 38 and $44 \mathrm{~g}$; and 2,058 and $2098 \mathrm{~g}$, respectively. A.M. Ulmer-Franco et al. [13] in their study demonstrated that the day-old live weights of the offspring of 29- and 59-week-old meat chickens of Cobb 500 cross were 37.3 and $48.9 \mathrm{~g}$, and after 42-day incubation their weights were 2,441.1 and 2,505.9 g. Therefore, two independent studies [13, 56] performed at an interval of 33 years in the chicken genotypes that differ significantly from each other in meat productivity, demonstrated that these values worsened with mother's age.

This relationship is associated with an increase in the yolk-white ratio in eggs from hens as they age [7, 15, 17-19]. It is known that most of the energy consumed in the process of embryogenesis is provided by the yolk ingredients [33].

The safety of young birds is determined by several factors, including the natural body resistance, and the state of the immune system. A.M. UlmerFranco et al. [57] investigated the formation of maternal immunity in the offspring of 32-, 40- and 55-week-old chickens of Cobb 500 cross. The IgY concentrations in the yolk of fresh eggs increased with aging of chickens in terms of both relative $(8.1,9.3,11.3 \mathrm{mg} / \mathrm{g})$ and absolute values $(134.4,178.0,248.1 \mathrm{mg})$. The concentration of these antibodies, calculated for $1 \mathrm{~g}$ of the yolk sac weight of the day-old chicks, increased with the advancing age of the parents, that was to be expected considering the same correlation with their accumulation in the yolk of fresh eggs. However, when calculating the IgY levels in the yolk sac 
as a percentage of their amount in the yolk of fresh eggs, an inverse relationship was found: in chicks from 32-, 40- and 55-week-old hens, they were 55.4, 39.1 and $33.3 \%$, respectively. Consequently, the intensity of transporting these antibodies from the yolk sac into the chicken body varies in the offspring of parents of different ages.

The average mortality of chickens, which were produced in the Netherlands in 2004-2006 from 16,365 breeder flocks of meat chickens of different genotypes, during the first week of active life amounted to $1.82,1.02$ and $1.20 \%$, when the laying hens were 25, 38-44 and 60 weeks of age [58]. According to A.K. Osmanyan et al. [59], the average fertilization rates of 26-34-, 34-38-, 38-42- and 39-62-week-old hens were 17.6, 18.1, 15.5 and 5.5 chicks, respectively.

Consequently, the egg fertilization rates, the intensity of the water vapor and metabolic heat release through the eggshell, as well as the results of incubation and the quality of the resulting young stock change with the age of mothers (Tables 1 and 2).

Multivariate correlations between the egg quality parameters and the age of laying hens were reported. Haugh units prove to have three-factor associations with the age, time of laying eggs and the environmental temperature, while the relative share of eggs has a four-factor correlation (apart from those listed, also the poultry productivity tendency). In eggs from 65 -week-old ducks, a decrease in the shell thickness was revealed as compared to eggs from 25 -week birds, as well as the increased number of pores [60]. Therefore, the authors recommend to increase gradually air humidity up to 60,65 and $70 \%$ during the incubation of eggs from ducks aged 25-35, 36-55 and 56-65 weeks, respectively. The same technique is suggested to be applied when incubating chicken eggs [27].

\section{Changes in the quality of hatched eggs occurring with breeder flock aging}

\begin{tabular}{|c|c|c|c|}
\hline Parameter & Changes & Poultry species & Reference \\
\hline Weight & + & Chickens, ducks, turkeys & [13-16] \\
\hline Egg yolk: & & & \\
\hline $\begin{array}{l}\text { weight, yolk-white ratio } \\
\text { fatty acid contents }\end{array}$ & + & Chickens, ducks, turkeys & {$[15,17-19]$} \\
\hline oleic, linoleic & - & Ducks & [43] \\
\hline myristic, palmitic, stearic & + & Ducks & [43] \\
\hline myristic, linoleic & - & Chickens & [44] \\
\hline Eggshell: & & & \\
\hline $\begin{array}{l}\text { absolute weight } \\
\text { relative weight, thickness, tensile strength, impact }\end{array}$ & + & Chickens & {$[22]$} \\
\hline strength, calcium levels & - & Chickens, ducks, quail & {$[9,22-26]$} \\
\hline Cuticle & & & \\
\hline thickness, lipid content & - & Chickens & {$[31]$} \\
\hline $\begin{array}{l}\text { Water vapor and metabolic heat release through the } \\
\text { eggshell of the incubated eggs }\end{array}$ & + & Chickens, ducks, turkeys & {$[17,27,47]$} \\
\hline Duration of incubation & - & Chickens & {$[8,13,50]$} \\
\hline
\end{tabular}

\section{Reproductive parameters in hens at different stages of the egg production}

\begin{tabular}{l|c|c|cc}
\hline \multicolumn{1}{c}{ Parameter } & \multicolumn{3}{c|}{ Stage } & \multirow{2}{*}{ Reference } \\
\cline { 2 - 4 } & initial & middle & final & {$[45]$} \\
Fertilization rate, \% & 92.7 & 96.7 & 80.3 & 50.0 \\
Hatchability rate, \% & 66.0 & 86.0 & 45.3 & {$[12]$} \\
Weight of day-old chicks, g & 36.5 & 42.4 & 1.20 & {$[44]$} \\
Mortality of chickens up to 7 days of age, \% & 1.82 & 1.02 & 5.5 & {$[58]$} \\
Reproductive potential, chicks per layer & 17.6 & 18.1 & {$[59]$} & \\
\hline
\end{tabular}

The biochemical assimilation of deutoplasma nutrients in the embryo proceed with release of heat [33]. The fact that the amount of such heat increases with advanced age of the chicken mothers who produce the hatching eggs is of practical importance. In order to prevent hyperthermia in embryos, which negatively affects the development and quality of young stock [61], it is required 
to incubate the eggs from young and old birds in different cabinets, adjusting temperature and humidity.

The appropriateness of thermal training in poultry embryos has been established to increase the adaptive capability of young stock [62-65]. Obviously, the mode of such a training should be adjusted, taking into account the specific characteristics of embryogenesis (primarily, the amount of produced metabolic heat) arising from aging parents.

With advanced age of the breeder flock, there is both an increase in the weight of a hatching egg and a young bird, and an increase in the number of chickens who die in the pre- and postnatal periods of ontogenesis. One reason is a reduction in the egg incubation time as mothers age $[8,13,50]$. Therefore, the navel in the hatched chicks can be closed incompletely resulting in increased chances of penetration of the bacteria that cause inflammation of the navel and yolk sac (omphalitis) and increased mortality during the first week of life [58].

It should be kept in mind that, with aging of the breeder flock, variations in parameters characterizing the reproductive function may occur in the setting of other limiting factors, such as the environment and/or the diet composition. There is a correlation between the profile of FAs accumulated in the egg deutoplasma and the degree of FA assimilation by the embryos, age of parents, the content of fatty acids in the diet, humidity in the incubation period, as well as the heterogeneity of the small intestine development in chicks hatched from eggs of hens of different ages [39-44). Therefore, it is important to optimize the content of FAs and other ingredients in diets of breeder flocks of different poultry species, taking into account their age [66, 67].

The phenomenon of the reproductive function deterioration with age has been revealed in different species. A direct correlation was established between the incidence of Alzheimer's disease [68], Down's syndrome [69], autism [70] in children and the age of the parents, which exceeds 35-40 years at conception. One of the reasons underlying the correlation is an increased number of mutations in the cells of potential parents with age [71], which is probably due to decreased efficiency of the antioxidant system [72, 73] and reduced capabilities of neutralizing the produced free radicals and peroxides. In cattle, the differences in the production of gonadotropic and steroid hormones were established, as well as in the ovarian follicles in 13-14-year-old cows and their daughters aged 1-4 years [74].

Forced molting of hens in the breeder flock is an effective method of extending the period of egg production [75]. Changes in morphological and physiological processes in the body, caused by an induced molt, allow to regulate the egg productivity and, thus, the reproductive function. However, fertilization of eggs laid by a molted bird is reduced by 3-5\% [76] and the release of water vapor through the eggshell in the hatching eggs reaches $5.58 \mathrm{mg} /(\mathrm{day} \cdot 100 \mathrm{~g} \cdot \mathrm{kPa})$ compared to $4.76 \mathrm{mg} /($ day $\cdot 100 \mathrm{~g} \cdot \mathrm{kPa})$ before molting [27]. Therefore, it seems appropriate to study the reproductive function in chicken population, subjected to forced molting (primarily the growth and development of their offspring in different periods of ontogenesis). Comprehensive research will clarify the characteristics of the offspring ontogenesis and confirm or rule out the sustainability of obtaining young stock from these birds.

Therefore, with the breeder flock aging, the properties of hatching eggs change, and, consequently, the metabolism in the embryo and chicks. The egg weight and the yolk-white ratio are increased. In contrast, the eggshell quality (calcium content, thickness and strength) is reduced, which affects its permeability to water vapor, gases, metabolic heat, and microflora (it is known that the loss of egg weight during the incubation is inversely related to the thickness of 
the shell). The properties of the cuticle covering the eggshell are deteriorated, which also increases the probability of egg contents infection.

Fatty acids are selectively accumulated in the yolk, which is forming in the process of oogenesis, depending on the diet composition and the age of the mothers. The intensity with which the embryos assimilate the yolk lipids is mediated by the relevant changes in the enzyme activities, and the concentrations of ACTH and corticosterone. For embryos, which are the offspring of young mothers, a decreased lipid metabolism is considered typical, which leads to slower development and poorer outcomes of both the egg incubation and rearing chickens.

Rates of fertilization, hatchability of eggs, young stock production and general fertility negatively correlate with the age of the parents, while the embryo and chick mortality rates, as well as their body weight, in contrast, demonstrate a positive correlation. These patterns prove once again that a higher weight of an individual animal is not always indicative of an optimal state of health.

In the extreme age groups of parents, the chick mortality rates during rearing increases. The mothers at the end of their productive period produce the offspring earlier that the mothers of the younger age groups, however, it is associated with an increased number of sub-standard chickens.

Thus, with the breeder flock aging, the reproductive function of poultry gradually fails. The changes occurring in the quality of eggs, in the growth and development of embryos and chicks should be considered when ranging eggs, before setting them in an incubator, both by the weight and the age of parents, in order to form normalized batches and obtain the young stock with similar adaptive capabilities. Moreover, it is advisable to appropriately regulate the temperature and humidity mode during the incubation to compensate for the increased release of water vapor and metabolic heat through the eggshell.

\section{R E F E R E N C ES}

1. Onagbesan O.M., Metayer S., Tona K., Williams J., Decuypere E., B r g g e m a n V. Effects of genotype and feed allowance on plasma luteinizing hormones, follicle-stimulating hormones, progesterone, estradiol levels, follicle differentiation, and egg production rates of broiler breeder hens. Poultry Sci., 2006, 85(7): 1245-1258 (doi: 10.1093/ps/85.7.1245).

2. D u n n I.C., Sharp P.J. Effect of short day treatment and return to long days on the hypothalamic-pituitary-gonadotrophic function in aging domestic hens. Proc. Fourth International Symposium on Avian Endocrinology. Tokyo, 1988: 14-15.

3. J o y n e r C.J., P e d d i e M.J., T a y lo r T.G. The effect of age on egg production in the domestic hen. Gen. Comp. Endocrinol., 1987, 65(3): 331-336 (doi: 10.1016/0016-6480(87)90117-1).

4. Willi a m s J.B., S h a r p P.J. Age-dependent changes in the hypothalamo-pituitary-ovarian axis of a laying hen. Journal of Reproduction and Fertility, 1978, 53: 141-146 (doi: 10.1530/jrf.0.0530141).

5. Johnson P.A., D i cke rman R.W., B a h r J.M. Decreased granulosa cell, luteinizing hormone sensitivity and altered thecal estradiol concentration in the aged hen, Gallus domesticus. Biol. Reprod., 1986, 35(3): 641-646 (doi: 10.1095/biolreprod35.3.641).

6. Wils o n H.R. Interrelationships of egg size, chick size, posthatching growth and hatchability. World's Poultry Sci. J., 1991, 47(1): 5-20 (doi: 10.1079/WPS19910002).

7. Fis in in V.I., Tu chemski i L.I., S a la mat in A.V., Z Zuravlev I.V., Do1g o ru k ov a A.M. Sel'skokhozyaistvennaya biologiya [Agricultural Biology], 2008, 6: 33-39 (in Russ.). Available http://www.agrobiology.ru/6-2008fisinin.html. No date.

8. Almeida J., Vieira S., Re is R., B erres J., Barros R., Ferreira A., Furtad o F. Hatching distribution and embryo mortality of eggs laid by broiler breeders of different ages. Revista Brasileira de Ciência Avícola, 2008, 10(2): 89-96.

9. A l e k s e v F.F., B e ly a k o v a L.S. Materialy XVI Mezhdunarodnoi konferentsii VNAP «Dostizheniya $v$ sovremennom ptitsevodstve: issledovaniya $i$ innovatsii» [Proc. XVI Int. Conf. WSAP «Modern commercial poultry: studies and innovations». Sergiev Posad]. Sergiev Posad, 2009: 171-173 (in Russ.).

10. Dy ad i chkina L.F., Pozdny a ova N.S. Materialy XVI Mezhdunarodnoi konferentsii $V N A P$ «Dostizheniya $v$ sovremennom ptitsevodstve: issledovaniya $i$ innovatsii»[Proc. KHVI Int. 
Conf. WSAP «Modern commercial poultry: studies and innovations». Sergiev Posad]. Sergiev Posad, 2009: 189-191 (in Russ.).

11. Dy a d i chk in a L.F., Ts il i nsk a y T.V. Ptitsa i ptitseprodukty, 2011, 5: 39-43 (in Russ.).

12. Yassin H., Velthuis A., B o erjan M., van Riel J., Huirne R. Field study on broiler eggs hatchability. Poultry Sci., 2008, 87(11): 2408-2417 (doi: 10.3382/ps.2007-00515).

13. U $1 \mathrm{mer}-\mathrm{Franco}$ A.M., F a s e n k o G.M., O' D e a C.E. Hatching egg characteristics, chick quality, and broiler performance at 2 breeder flock ages and from 3 egg weights. Poultry Sci., 2010, 89(12): 2735-2742 (doi: 10.3382/ps.2009-00403).

14. Odabasi A.Z., Miles R.D., B a laban M.O., Portier K.M. Shanges in brown eggshell color as the hen ages. Poultry Sci., 2007, 86(2): 356-363 (doi: 10.1093/ps/86.2.356).

15. A p plegate T.J., Harper D., Lilburn M.S. Effect of hen production age on egg composition and embryo development in commercial Pekin ducks. Poultry Sci., 1998, 77(11): 16081612 (doi: 10.1093/ps/77.11.1608).

16. A p p legate T.J., Lilburn M.S. Effect of hen age, body weight, and age at photostimulation. 1. Egg, incubation, and poult characteristics of commercial turkeys. Poultry Sci., 1998, 77(3): 433-438 (doi: 10.1093/ps/77.3.433).

17. Hamidu J., Fasenko G., Guan L., Barreda D., Feddes J. Influence of parent flock age on embryonic metabolism in modern turkey strains. Poultry Sci., 2011, 90(2): 426-434 (doi: 10.3382/ps.2010-00967).

18. Peebles E.D., Gardner C.W., Brake J., Benton C.E., Bruzual J.J., Gera rd P.D. Albumen height and yolk and embryo compositions in broiler hatching eggs during incubation. Poultry Sci., 2000, 79(10): 1373-1377 (doi: 10.1093/ps/79.10.1373).

19. Ahn D.U., Ki m S.M., Sh u H. Effect of egg size and strain and age of hens on the solids content of chicken eggs. Poultry Sci., 1997, 76(6): 914-919 (doi: 10.1093/ps/76.6.914).

20. Johnston S., Gous R. Modelling the changes in the proportions of the egg components during a laying cycle. Brit. Poultry Sci., 2007, 48(3): 347-353 (doi: 10.1080/00071660701381134).

21. Roberts J.R. Factors affecting egg internal quality and eggshell quality in laying hens. $J$. Poultry Sci., 2004, 41(3): 161-177 (doi: 10.2141/jpsa.41.161).

22. Rayan G., Galal A., F a thi M., E 1 - A t t a r A. Impact of layer breeder flock age and strain on mechanical and ultrastructural properties of eggshell in chicken. International Journal of Poultry Science, 2010, 9(2): 139-147 (doi: 10.3923/ijps.2010.139.147).

23. Gualhanone A., Furlan R., Fernandez-Alarcon M., Macari M. Effect of breeder age on eggshell thickness, surface temperature, hatchability and chick weigh. Braz. J. Poultry Sci., 2012, 14: 9-14 (doi: 10.1590/S1516-635X2012000100002).

24. Ts a re nko P.P., V a s i l'e va L.T., O s i pova E.V. Ptitsa i ptitseprodukty, 2012, 5: 51-54 (in Russ.).

25. S e reda T.I., D e rk ho M.A. Sel'skokhozyaistvennaya biologiya [Agricultural Biology], 2011, 2: 72-76 (in Russ.). Available http://www.agrobiology.ru/2-2011sereda.html. No date.

26. Al- B at shan H.A., S c e id e le r S.E., B la ck B.L., G a rli ch J.D., And e rson K.E. Duodenal calcium uptake, femur ash and eggshell quality decline with age and increase following molt. Poultry Sci., 1994, 73(10): 1590-1596 (doi: 10.3382/ps.0731590).

27. Meir M., Ar A. Changes in eggshell conductance, water loss and hatchability of layer hens with flock age and moulting. Brit. Poultry Sci., 2008, 49(6): 677-684 (doi: 10.1080/00071660802495288).

28. Kemps B.J., Govaerts T., De Ketelaere B., Mertens K., Bamelis F.R., B a i n M.M., De cuypere E.M., De Baerde ma eker J.G. The influence of line and laying period on the relationship between different eggshell and membrane strength parameters. Poultry Sci., 2006, 85(7): 1309-1317 (doi: 10.1093/ps/85.7.1309).

29. Rodriguez-Navarro A., Kali n O., Nys Y., Garcia-Ruiz J.M. Influence of the microstructure on the shell strength of eggs laid by hens of different ages. Brit. Poultry Sci., 2002, 43(3): 395-403 (doi: 10.1080/00071660120103675).

30. J o n e s D.R., A nde rs o n K.E., C u rt is P.A., J o n e s F.T. Microbial contamination in inoculated shell eggs: I. Effects of layer strain and hen age. Poultry Sci., 2002, 81(5): 715-720 (doi: $10.1093 / \mathrm{ps} / 81.5 .715$ ).

31. Rodríguez-Navarro A., Domínguez-Gasca N., Mucoz A., Ortega$\mathrm{Hu}$ ertas M. Change in the chicken eggshell cuticle with hen age and egg freshness. Poultry Sci., 2013, 92(11): 3026-3035 (doi: 10.3382/ps.2013-03230).

32. Nangsuay A., Ruangpanit Y., Meijerhof R., Attamangkune S. Yolk absorption and embryo development of small and large eggs originating from young and old breeder hens. Poultry Sci., 2011, 90(11): 2648-2655 (doi: 10.3382/ps.2011-01415).

33. Ro m a n off A.L. Biochemistry of Avian Embryo. Wiley, NY, 1967.

34. Latour M.A., P e ebles E.D., Doyle S.M., Pansky T., S mith T.W., B oyle C.R. Broiler breeder age and dietary fat influence the yolk fatty acid profiles of fresh eggs and newly hatched hicks. Poultry Sci., 1998, 77(1): 47-53 (doi: 10.1093/ps/77.1.47).

35. Noble R.C., Lonsdale F., Conner K., B rown D. Changes in lipid metabolism in the chick embryo with parental age. Poultry Sci., 1986, 65(3): 409-416 (doi: 10.3382/ps.0650409).

36. N oble R.C., Shand J.H. Unsaturated fatty acid compositional changes and desaturation during the embryonic development of the chicken (Gallus domesticus). Lipids, 1985, 20(5): 278- 
282 (doi: 10.1007/BF02534260).

37. Mandon E.C., de Gomez Dumm I.N.T., de Alaniz M.J.T., Marra C.A., $\mathrm{Br}$ e n n e r R.R. ACTH depresses delta 6 and delta 5 desaturation activity in rat adrenal gland and liver. J. Lipid Res., 1987, 28(12): 1377-1382.

38. L a t o u r M.A., La iche S.A., Thomps o n J.R., Pond A.L., P e ebles E.D. Continuous infusion of adrenocorticotropin elevates circulating lipoprotein cholesterol and corticosterone concentrations in chickens. Poultry Sci., 1996, 75(11): 1428-1432 (doi: 10.3382/ps.0751428).

39. Yalç in S., I z z e to ğlu G.T., A kt a A. Effects of breeder age and egg weight on morphological changes in the small intestine of chicks during the hatch window. Brit. Poultry Sci., 2013, 54(6): 810-817 (doi: 10.1080/00071668.2013.860212).

40. Burnham M.R., Peebles E.D., Gardner C.W., Brake J., Bruzual J.J., $\mathrm{G}$ e r a rd P.D. Effects of incubator humidity and hen age on yolk composition in broiler hatching eggs from young breeders. Poultry Sci., 2001, 80(10): 1444-1450 (doi: 10.1093/ps/80.10.1444).

41. Pe ebles E., Doyle S., Pansk T., Gerard P., Lat our M., B oyle C., S mith T. Effects of breeder age and dietary fat on subsequent broiler performance. 1. Growth, mortality, and feed conversion. Poultry Sci., 1999, 78(4): 505-511 (doi: 10.1093/ps/78.4.505).

42. Tullett S.G. Science and the art of incubation. Poultry Sci., 1990, 69(1): 1-15 (doi: $10.3382 /$ ps.0690001).

43. Onba Ş 1 la r E.E., Erde m E., Poyraz Ö., Yalçın S. Effects of hen production cycle and egg weight on egg quality and composition, hatchability, duckling quality, and first-week body weight in Pekin ducks. Poultry Sci., 2011, 90(11): 2642-2647 (doi: 10.3382/ps.2011-01359).

44. Yilmaz-Dikmen B., Sahan U. The relationship among age, yolk fatty acids content, and incubation results of broiler breeders. Poultry Sci., 2009, 88(1): 185-190 (doi: 10.3382/ps.2008-00068).

45. B ergoug H., Burel C., Guinebretière M., Tong Q., Roulston N., Romanini C.E.B., Exadaktylos V., Mcgonnell I.M., Demmers T.G.M., Verhelst R., Bahr C., B e rckmans D., Eterradossi N. Effect of pre-incubation and incubation conditions on hatchability, hatch time and hatch window, and effect of post-hatch handling on chick quality at placement. World's Poultry Sci. J., 2013, 69(2): 313-334 (doi: $10.1017 /$ S0043933913000329).

46. Ha midu J.A., Fas enko G.M., Feddes J.J.R., O'Dea E.E., O uellet te C.A., Win e land M.J., Christe ns e n V.L. The effect of broiler breeder genetic strain and parent flock age on eggshell conductance and embryonic metabolism. Poultry Sci., 2007, 86(11): 2420-2432 (doi: 10.3382/ps.2007-00265).

47. Nangsuay A., Meijerhof R., Ruangpanit Y., Kemp B., van den Brand H. Energy utilization and heat production of embryos from eggs originating from young and old broiler breeder flocks. Poultry Sci., 2013, 92(2): 474-482 (doi: 10.3382/ps.2012-02643).

48. Tzschentke B., Plage mann A. Imprinting and critical periods in early development. World's Poultry Sci. J., 2006, 62(4): 626-635 (doi: 10.1017/S0043933906001176).

49. A r te m o v D.V. Problemy biologii produktivnykh zhivotnykh, 2014, 1: 5-20 (in Russ.).

50. Hudson B.P., Fairchild B.D., Wilson J.L., Dozi e r W.A., Buh r R.J. Breeder age and zinc source in broiler breeder hen diets on progeny characteristics at hatching. J. Appl. Poultry Res., 2004, 13(1): 55-64 (doi: 10.1093/japr/13.1.55).

51. Z a b udski i Yu.I. Ptitsevodstvo, 2004, 2: 13 (in Russ.).

52. Christensen V.L., Noble D.O., Nestor K.E. Influence of selection for increased body weight, egg production, and shank width on the length of the incubation period of turkeys. Poultry Sci., 2000, 79(5): 613-618 (doi: 10.1093/ps/79.5.613).

53. Zabudski i Yu.I. Reproductive function in hybrid poultry. I. An impact of breeding for productivity traits (review). Agricultural Biology, 2014, 4: 16-29 (in Engl., in Russ.) (doi: 10.15389/agrobiology.2014.4.16eng, doi: 10.15389/agrobiology.2014.4.16rus).

54. Tanure C., Cafe M.B., Leandro N.S.M., Baiao N.C., Stringhini J.H., $\mathrm{G}$ o m e s N.A. Effects of ages of light breeder hens and storage period of hatchable eggs on the incubation efficiency. Arquivo Brasileiro de Medicina Veterináriae Zootecnia, 2009, 61(6): 13911396 (doi: 10.1590/S0102-09352009000600019).

55. Dyadichkina L.F., Gupalo I.M., Pozdnyakova N.S., Melekhina T.A. Dostizheniya nauki i tekhniki APK, 2014, 5: 40-42 (in Russ.).

56. M c N a ughto n J.L., D e at o n J.W., R e e ce F.N., Hay nes R.L. Effect of age of parents and hatching egg weight on broiler chick mortality. Poultry Sci., 1978, 57(1): 38-44 (doi: $10.3382 / \mathrm{ps} .0570038)$.

57. U $1 \mathrm{mer}-\mathrm{Franco}$ A.M., Cherian G., Quezada N., Fasenko G.M., Mc Mulle n L.M. Hatching egg and newly hatched chick yolk sac total IgY content at 3 broiler breeder flock ages. Poultry Sci., 2012, 91(3): 758-764 (doi: 10.3382/ps.2011-01757).

58. Yassin H., Velthuis A., B o erjan M., van Riel J. Field study on broilers' firstweek mortality. Poultry Sci., 2009, 88(4): 798-804 (doi: 10.3382/ps.2008-00292).

59. O smany a A.K., Rybakov D.I., Y 1 love $\mathrm{nko}$ A.V., G a lk in V.A. Ptitsa i ptitseprodukty, 2014, 5: 46-48 (in Russ.).

60. E 1-Han ou n A.M., Rizk R.E., Shahe in E.H.A., Has s a n N.S., B rake J. Effect of 
incubation humidity and flock age on hatchability traits and posthatch growth in Pekin ducks. Poultry Sci., 2012, 91(9): 2390-2397 (doi: 10.3382/ps.2011-02075).

61. Zabudski i Yu.I., K is e lev L.Yu., Delyan A.S., Kamalov R.A., Golikova A.P., Fed o se e va N.A., Mys h ki na M.S. Problemy biologii produktivnykh zhivotnykh, 2012, 1: 5-16 (in Russ.).

62. Shinder D., Rus a l M., Giloh M., Ya hav S. Effect of repetitive acute cold exposures during the last phase of broiler embryogenesis on cold resistance through the life span. Poultry Sci., 2009, 88(3): 636-646 (doi: 10.3382/ps.2008-00213).

63. Yalçi in S., B a b a c a n o glu E., Gule r H., A k şi t M. Effects of incubation temperature on hatching and carcass performance of broilers. World's Poultry Sci. J., 2010, 66(1): 87-93 (doi: 10.1017/s0043933910000097).

64. Zabudski i Yu.I., Golik ova A.P., Fedos e e va N.A. Sel'skokhozyaistvennaya biologiya [Agricultural Biology], 2012, 4: 14-21 (in Russ.). Available http://www.agrobiology.ru/42012zabudskyi.html. No date.

65. Zabudski i Yu.I., S huvalova M.V. Materialy XVII Mezhdunarodnoi konferentsii VNAP "Innovatsionnye razrabotki $i$ ikh osvoenie $v$ promyshlennom ptitsevodstve» [Proc. XVII Int. Conf. WSAP «Innovative developments in poultry and their practical use»]. Sergiev Posad, 2012: 240 242 (in Russ.).

66. Tu chemski i L.I., Egorov I.A., G ladkova G.V., S a lgereev S.M., N a z a r ov V.G., Emanuilova Zh.V., Goloves hchenko A.A., S mirnov D.D., Muk $\mathrm{h}$ a $\mathrm{m} \mathrm{m}$ ed ov Z.R. Rukovodstvo po vyrashchivaniyu i soderzhaniyu roditel'skogo stada myasnykh kur [Guidelines for rearing breeder meat chicken. Sergiev Posad]. Sergiev Posad, 2011 (in Russ.).

67. Okolelova T., Mansurov R., Novikov V. Ptitsevodstvo, 2012, 4: 17 (in Russ.).

68. Bertram L., Busch R., Spiegl M., Lautenschlager N., Müller U., Kurz A. Paternal age is a risk factor for Alzheimer disease in the absence of a major gene. Neurogenetics, 1998, 1(4): 277-280 (doi: 10.1007/s100480050041).

69. Girirajan S. Parental-age effects in Down syndrome. J. Genet., 2009, 88(1): 1-7 (doi: 10.1007/s12041-009-0001-6).

70. Shelton J., Tancredi D., Hertz-Picciotto I. Independent and dependent contributions of advanced maternal and paternal ages to autism risk. Autism Res., 2010, 3(1): 30-39 (doi: 10.1002/aur.116).

71. Wyrobek A.J., Eskenazi B., Young S., Arnheim N., Tiemann-Boege I., J abs E.W., G las e r R.L., P e ars on F.S., Evens on D. Advancing age has differential effects on DNA damage, chromatin integrity, gene mutations, and aneuploidies in sperm. PNAS USA, 2006, 103(25): 9601-9606 (doi: 10.1073/pnas.0506468103).

72. Fis in in V.I., Surai P.F., Kuznetsov A.I., M iftakhutdinov A.V., Ter$\mathrm{m}$ a n A.A. Stressy $i$ stressovaya chuvstvitel'nost' kur $v$ myasnom ptitsevodstve. Diagnostika $i$ profilaktika: monografiya [Stresses and stress sensitivity in meat poultry - Diagnosis and prevention]. Troitsk, 2013 (in Russ.).

73. S u r a i P., F i s i n i n V.I. The modern anti-stress technologies in poultry: from antioxidants to vitagenes. Agricultural Biology, 2012, 4: 3-13 (in Engl., in Russ.) (doi: 10.15389/agrobiology.2012.4.3eng, doi: 10.15389/agrobiology.2012.4.3rus).

74. Malhi P., Adams G., Singh J. Bovine model for the study of reproductive aging in women: follicular, luteal, and endocrine characteristics. Biol. Reprod., 2005, 73(1): 45-53 (doi: 10.1095/biolreprod.104.038745).

75. K is e lev L.Yu., Z abu d ski i Yu.I., Klopov M.I., Novi k ova N.N., K is e lev V.L., Pli e va T.Kh. Problemy biologii produktivnykh zhivotnykh, 2012, 1: 52-55 (in Russ.).

76. Fis in i n V.I., K o n o p leva A.P. About physiological and morphological processes in poultry at natural and induced molting. Agricultural Biology, 2015, 50(6): 719-728 (in Engl., in Russ.) (doi: 10.15389/agrobiology.2015.6.719eng, doi: 10.15389/agrobiology.2015.6.719rus).

\section{Events}

The 1st International Conference on

\section{FOOD BIOACTIVES}

\section{\& HEALTH}

13-15 September 2016

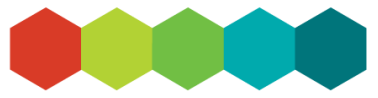

Norwich, UK
We are pleased to announce the $1^{\text {st }}$ International Conference on Food Bioactives and Health to be held in the fine city of Norwich, UK on 13-15 September, 2016. FBHC2016 will provide an open forum that brings together researchers from various scientific communities to present the latest research and discuss common themes and challenges to understanding the impacts of food bioactives on health.

Contacts: dawn.rivett@ifr.ac.uk Institute of Food Research Norwich Research Park, Norwich, NR4 7UA, UK

Information: http://www.globaleventslist.elsevier.com/events/2016/09/the-1st-internationalconference-on-food-bio 